\title{
Internal versus External Representation
}

I argue that there are two kinds of representation, whose joint recognition promises, among other things, to provide a relatively clear and unified account of both pictorial representation and fictional reference.

To begin, I shall show by demonstrating an apparent ambiguity in the concept of representation that it has two distinct aspects. One standard test for ambiguity of a concept $C$ is to find a case in which $\mathrm{C}$ both is and is not applicable to some object or objects; then one may proceed to repair the damage by distinguishing different senses, aspects, or varieties of the concept "C." Here is a pictorial test case of this kind for the concept of representation.

First, it is surely true that a picture $\mathrm{P}$ might represent a man, even if there is no actual man about whom it is true that he is the man thus represented by picture P. For the person who painted A might have intended merely to represent " $a$ man," without having any particular actual man in mind.

However, if there is no actual man represented by picture $\mathrm{P}$, then there is a clear sense in which $\mathrm{P}$ does not represent "a man"- at least not in the sense in which it would represent "a man" if there were some actual man whom it represented.

At the same time, though, to repeat, clearly picture P might still represent "a man" in the first sense above, in that, if the artist's painting is successful, then it will "represent a man," in spite of the fact that it does not represent "a man" in the sense of an actual man.

Now to be sure, the ambiguity here might be argued to be located primarily in the whole phrase "representation of a man," or in different senses of "a man" in each case, rather than in the concept of representation itself. Nevertheless, the case at least shows the need to distinguish two fundamentally different aspects or categories of representation - each of which is generically describable as "representation by a picture $\mathrm{P}$ of some thing X." We confuse these two fundamentally different aspects at our peril. Thus the label "ambiguous" will remain descriptively convenient for such phrases as " $\mathrm{P}$ is a representation of a man," and thus derivatively as applied to the concept of representation itself, even if it is only (very) different kinds of use, or different aspects, of that concept that are actually involved.

As for the evidence I have used to establish the ambiguity in question, it is arguably not controversial at all, since it is recognized already. For example: Richard Wollheim distinguishes representations of particular objects, or events, from representations of objects or events "that are merely of a particular kind," and thus of $a$ man, and so on, rather than of some particular man; ${ }^{1}$ whereas Kendall Walton uses the fact that a picture can represent a man, even though there is no actual man thus represented, as part of his case that the concept of representation is primarily to be understood not in object-centered ways, but rather in terms of his own "props used in imaginative games" approach. ${ }^{2}$ Nelson Goodman, in the face of such examples, distinguishes a picture of a man from a man-picture, in cases where no actual man is represented. $^{3}$

However, by focusing on the fact that examples such as the above show that there is an apparent, or at least formal, ambiguity in the concept of representation, I hope to facilitate the raising of issues and approaches that have not yet been adequately investigated.

First, I shall distinguish the relevant distinct concepts or aspects of representation as external 
versus internal (or outer versus inner) representation. External or outer representation by a picture $\mathrm{P}$ is about cases in which there is some actual object $\mathrm{X}$, normally external to the representing object $\mathrm{P},{ }^{4}$ that is represented by $\mathrm{P}$. Thus, for example, picture $\mathrm{P}$ externally represents $a$ man just in case there is some actual man, distinct from $\mathrm{P}$, who is represented or portrayed by $\mathrm{P} .5$

However, the formulation of a corresponding characterization of internal or inner representation is inevitably more controversial. Here is an initial attempt: internal or inner representation is about whether there is an object $\mathrm{X}^{\prime}$, that is internal to the object $\mathrm{P}$, and that is represented by $\mathrm{P}$.

\section{ALLAYING ANXIETIES}

That the above characterization of internal representation is inevitably controversial can be seen by giving a substitution-instance of it: picture $\mathrm{P}$ internally represents a man just in case there is a man, who is internal to $\mathrm{P}$, and who is represented by $\mathrm{P}$.

This instance is likely to raise logical and metaphysical hackles on at least two grounds: first, it clearly involves reference to, and reidentification of, "the man" in question (since it seems to be said that there is such a man and that that same man is both internal to $\mathrm{P}$ and represented by $\mathrm{P}$ ); second, metaphysical worries about how "a man" could possibly be "internal" to a picture $P$.

Indeed, it seems likely that these, or related, logical and metaphysical obstacles have proved formidable enough to dissuade previous attempts at distinguishing an internal aspect, or kind, of representation from its more conventionally accepted external aspect or kind.

Here is a preliminary attempt to allay the above logical and ontological anxieties. The issues revolve around the status of the phrase "there is" in the definition. On my account, this phrase is merely part of a claim that "there is" an object of reference $\mathrm{X}^{\prime}$ that is internally represented by a picture. In other words, this "there is" has no specifically ontological implications as to the status of any given such object of reference; instead it functions to indicate that statements of inner representation are indeed referential, in that they involve a reference to some object. ${ }^{6}$
A more specifically ontological anxiety is a concern that an account of internal representation might be committed to the existence of such internal objects, since, of course, the idea of an actually existing man as somehow being internal to a picture of him seems confused or even self-contradictory. However, my reply is that a general account of internal representation must inevitably include cases of internal objects that do not exist, since they are fictional in a broad sense-such as with pictures of unicorns, or Santa Claus, or of a character in some fictional novel or play. This again shows that the referential form of statements of internal representation does not in itself have any ontological implications as to the status of any particular objects that are thus referred to. ${ }^{7}$

Nevertheless, this referential view is still distinctively different from a nonreferential view such as Goodman's, which distinguishes a genuine picture of a man from a man-picture, which term he invokes when no actual man is pictured, and which description merely classifies the picture as being of a certain kind, whose extension is the set of man-pictures. ${ }^{8}$ Thus, on my account, but not on Goodman's, "picture of $\mathrm{X}$ " is always genuinely relational.

I shall further discuss the validity and ontological harmlessness of reference to fictional entities in Sections VIII and IX.

\section{MORE ON REPRESENTATIONAL AMBIGUITY}

Returning to the suggested ambiguity in the concept of representation, recall that at least the unanalyzed ambiguity, and the evidence on which it rests, is not controversial: that a picture can represent a man, without there actually being such a man, cannot be denied. Thus, the initial issue is, of course, as to how linguistic contexts such as "picture P represents a man" should be analyzed, in cases when there is not any actual corresponding man represented by $\mathrm{P}$.

I take it it would usually be assumed that this initial case just shows that there is a unitary concept of representation, which, among other things, is such that "P represents $X$ " does not entail "there is an actual X represented by P." However, that nonentailment can be explained equally well by postulating two distinct concepts of representation, on one of which, 
namely, internal representation, the entailment does not hold, while on the other (external representation) the entailment does hold. ${ }^{9}$ For it is clear that standard examples of the nonentailment in question would, on my account, be cases of internal rather than external representation, and, hence, be adequately explained by that concept of internal representation.

Moreover, the issue of ambiguity is not so easy to evade, because, for instance, one could see or recognize that a picture $\mathrm{P}$ represented "a man," whether or not there was, independently of one's act of perception, some actual man who was represented by picture P. Thus, it is hard to deny that one could, on the one hand, have conclusive perceptual evidence that a picture P represents someone-which "someone" one would describe or recognize as "a man"quite independently of whether one also has any evidence that something else, an actual man, is represented by picture $\mathrm{P}$. Thus from an epistemic perspective the relevance or applicability of two distinct concepts of representation-or of two distinct kinds of "object" of the concept-seems to be an inescapable part of the joint evidentiary situation in such a case.

Hence, I would claim that, in spite of any initial difficulties or obstacles in defining internal representation, some analysis should be attempted of that concept, that adequately captures or allows for such epistemic differences, as well as being acceptable on logical and metaphysical grounds.

\section{POSSIBLE OBJECTIONS}

Before giving my account of internal representation, there is a major issue that needs to be discussed, namely, the function or purpose of a concept of internal representation in cases where there is an external representation by picture $\mathrm{P}$ of object X. I shall argue in Section VI that in such cases internal representation still has an important epistemic role to play, in that it is at least partly in virtue of seeing what a picture $\mathrm{P}$ internally represents-its object $\mathrm{X}^{\prime}$ - that one can justify a claim that $\mathrm{P}$ externally represents object X.

But there is a potential basic objection to such an approach, namely, that when external representation obtains, there would be no such theoretical need, or room, for a concept of internal representation in addition to that of external representation, so that its general postulation for all cases of representation is ad hoc. ${ }^{10}$

This objection could take two forms. First, that in cases of external representation of an object $\mathrm{X}$ by picture $\mathrm{P}$, the object $\mathrm{X}^{\prime}$ that one sees when looking at $\mathrm{P}$ is $X$ itself, so that there is no distinct object $X^{\prime}$ available, which could serve as the object of an independent kind of "internal" representation. I shall call this the "seeing through" objection, in that on this account one "sees through" an external representation $\mathrm{P}$ of object $\mathrm{X}$ to its actual object $\mathrm{X}$.

And second, it might be argued that whether or not the "seeing through" view is correct in some or all cases, epistemic claims that picture $P$ externally represents object $X$ can be justified on other, nonreferential grounds, such as by claiming that $\mathrm{P}$ has a group of properties that are its "representational content"- those properties it represents $\mathrm{X}$ as having-which explain P's ability to externally represent $X$ without introducing any independent object $\mathrm{X}^{\prime}$ that is internally represented. ${ }^{11} \mathrm{I}$ take it that this second, more general objection - the "nonreferential" objection-embodies a view that is the common core of most extant views of representation, whatever else they disagree on.

Since my purpose in this paper is not primarily polemical, I shall address such nonreferential views only indirectly, via the above mentioned epistemic justification argument, which at least will show that nonreferential views could not provide a complete account of representation. But I shall attempt to refute the first, "seeing through" view of external representation, since versions of it-holding that any genuine representational reference could only be to an external object of reference-constitute a more immediate threat to my approach.

\section{THE IMPOSSIBILITY OF SEEING THROUGH}

I shall show that perceptual access to a picture $\mathrm{P}$ of actual object $X$ does not give the perceiver perceptual access to $X$ itself - so that, even if there is something X-related that one sees when looking at picture $\mathrm{P}$, that something cannot be $\mathrm{X}$ itself. Call this the "no seeing through," or NST thesis. 
To begin, the obvious point should be made that a picture $\mathrm{P}$ of some actual object $\mathrm{X}$ is not itself identical with that object $\mathrm{X} .{ }^{12}$ Thus, there is a straightforward, veridical perceptual sense in which, if one sees picture $\mathrm{P}$ of an actual person $\mathrm{X}$, one does not thereby - that is, simply in virtue of seeing picture $\mathrm{P}$ itself-also see person $\mathrm{X}$, because, of course, $\mathrm{P}$ is not $\mathrm{X}$, and therefore it could not correctly be seen to be $\mathrm{X}$. This point remains valid whether or not object $\mathrm{P}$ is a picture or representation of $\mathrm{X}$.

Second, I want to extend this point to cover, not just direct seeing of $P$ itself, but any kind of perceptual access to, or perceptual involvement with $\mathrm{P}$ in which a viewer's gaze is directed upon picture $\mathrm{P}$, including cases in which the viewer's interpretation of what she sees is primarily $X$-related rather than $P$-related, so that on some analyses she would, strictly speaking, no longer be seeing $\mathrm{P}$ itself. Thus if the general formula "Viewer A sees picture $\mathrm{P}$ of object X" is considered, I wish to also consider cases in which substitution-instances of that formula do not entail "Viewer A sees picture P."

For example, a trompe l'oeil picture $\mathrm{P}$ of object $\mathrm{X}$ is such that, when a viewer's gaze is directed upon that picture $\mathrm{P}$ under normal conditions, the viewer is perceptually aware only of something X-related, rather than of picture $\mathrm{P}$ itself, so that in some sense she does not perceive picture $P$ itself.

Nevertheless, I want to claim for these extended cases too that, since picture $\mathrm{P}$ is not itself identical with object $\mathrm{X}$, then Viewer A, merely by virtue of having perceptual access to $\mathrm{P}$, does not thereby gain perceptual access to $\mathrm{X}$ itself. Thus, I would claim that the conjunction of:

(1) Viewer A sees picture P of object X, and

(2) Viewer A does not see object X independently of her perceptual access to $\mathrm{P}$ entails

(3) Viewer A does not see object X.

Statement (2) is needed to rule out a case in which, for instance, Viewer A's perceptual field includes both a picture $\mathrm{P}$ of $\mathrm{X}$, and, independently of that picture, $X$ itself-because, of course, our interest is only in what is entailed by perceptual access solely to picture $\mathrm{P}$ itself.
More informally or intuitively, my point is this: there is no magical way in which, merely by looking at a picture $\mathrm{P}$ of some actual object $\mathrm{X}$-which picture is not identical with $\mathrm{X}$-one can thereby get to see $X$ itself, no matter how one explains or analyzes what is involved in having perceptual access to picture $\mathrm{P}$, and of what is involved in P's having representational qualities such that it represents X. For perceptual claims are veridical, no matter what interpretive juggling or rearranging goes on with respect to "what one sees" in such a case. So that if $\mathrm{P}$ is not $\mathrm{X}$, then one cannot correctly be said to see $X$, solely in virtue of one's looking at $\mathrm{P}$, whether or not $\mathrm{P}$ is a representation of $\mathrm{X}$, and whatever is the correct analysis of " $\mathrm{P}$ is a representation of X."

Next, I shall discuss an attempt to escape this conclusion via a claim that some pictures are "visual prostheses," that is, that they are like devices such as eyeglasses or binoculars, through which one is indeed able to see actual objects such as X. ${ }^{13}$ However, I shall show that, insofar as it is true that one is able to see $\mathrm{X}$ itself while looking at or through such a device, it follows that the device in question is not a representation of $\mathrm{X}^{14}$

Some who argue for the "visual prosthesis" view, such as Walton and Lopes, do so by invoking the concept of counterfactual dependence-that if some visual properties of the actual object $\mathrm{X}$ had been different, then the corresponding properties of the prosthesis would have been different. ${ }^{15}$ However, that backwardlooking, past tense concept is arguably irrelevant to issues about actually seeing $X$ through a genuine prosthetic device. What is instead needed for genuine seeing of $\mathrm{X}$ is a forwardlooking counterfactual dependence, or an FCD concept: that if some visual properties of the object X were to become different, then the corresponding properties of the prosthesis would become different. For it is characteristic of actually seeing an object $X$ through such a device that changes in the object itself result in changes in the properties one sees it to have in real time (in the future or the continuous present).

But if one were to record such changes on videotape, that recording itself would no longer be able to change its properties to reflect any current and continuing changes in $\mathrm{X}$. Thus, in viewing or seeing that videotape, one would no 
longer be seeing $X$ itself, but only a picture of $\mathrm{X}$, since that picture is not forward counterfactually dependent on $\mathrm{X}$. Thus, on this analysis, genuine seeing of $\mathrm{X}$ through a prosthesis simply is a seeing of $X$ itself rather than of some representation of $\mathrm{X}$; whereas when one does see a representation of $\mathrm{X}$, it does not have the FCD relation to $\mathrm{X}$ itself, and, hence, does not count as an actual seeing of $X$.

Because of the importance of the current issue, I shall also provide another, noncounterfactual analysis of the differences between prosthetic and representational seeing, which in addition involves only changes in relational rather than inherent properties. A useful bridge concept in the discussion is that of (what could be called) environmental stability. A representation $\mathrm{R}$ of object $\mathrm{X}$ is environmentally stable (hereafter: stable) in the sense that $\mathrm{R}$ will continue to be a representation of $\mathrm{X}$ through normal changes in its position or environment, such as its being moved from room to room, or if other objects or persons change their position relative to the current position of representation R. Or, in more usual metaphysical terms, to say that an object $\mathrm{R}$ is an external representation of $\mathrm{X}$ is to attribute some nonrelational properties to it, in virtue of which it is able to externally represent X, and which nonrelational properties are independent of its other relational properties, such as its position relative to other objects in its environment.

However, visual prostheses are instead environmentally unstable, in that, obviously, what one sees through eyeglasses or binoculars will change as the seen objects are moved around, or if other objects are moved around relative to them. Thus, the price of being able to actually see the object $X$ itself through a visual prosthesis is that one's doing so depends on complex relational properties of the prosthesis, such as its having the right kind of visual alignment to one's eyes and to the actual object X. Hence, prostheses have a property, namely, instability, which stable representations necessarily lack, and so representations cannot be prostheses.

In more intuitive terms, the reason why a prosthesis cannot be a representation of $\mathrm{X}$ is because it could not stably represent $\mathrm{X}$, as opposed to any other things: it would "represent" whatever objects were appropriately aligned with it, and in thus "representing" anything, it would actually represent nothing.
Thus, I conclude, on the basis of both of these analyses, that the "prosthesis" defense of the claim that some pictures both represent some actual $\mathrm{X}$, and are such that in looking at them one can see $\mathrm{X}$ itself, must fail, and, hence, that it is never true that perceptual involvement with a representation of $\mathrm{X}$ involves a perceiving of $\mathrm{X}$ itself. Thus the "no seeing through," or NST, thesis is true for external representations.

\section{A WIDER CONTEXT}

The argument of this paper has been primarily focused on pictorial representation, but before continuing it will be useful to situate the discussion in a wider context. I would claim that any kind of external representation, including conventional linguistic kinds of signification, also involves an appropriate case of internal representation. Thus, broadly speaking, internal representation is concerned with internal referential aspects of meaning, intension, or content, ${ }^{16}$ whereas external representation is instead concerned with extension, or external, worldly reference.

In the arts, the internal representation thesis is primarily relevant to topics such as that of pictorial representation, and of fictional reference, and my announced epistemic argument for internal representation is primarily relevant to pictorial representation cases. Nevertheless, it is still useful to examine such cases in the broader context of both representational conventions and artistic intentions to represent actual subjects, even when such attempts end in failure, that is, with no external pictorial representation or depiction having occurred. ${ }^{17}$

I shall consider three putative kinds of representation, to be labeled signification, which is a bare reference to a subject, as in baptizing someone with a name; description, which characterizes something in some way, even if incorrectly; and standard or unqualified representation, our primary topic of interest. The three examples to be used all concern cases of putative portraiture of a subject B by artist A, so that our primary interest will be in the species of standard representation referred to as pictorial representation, or depiction. (The examples are brief-fully adequate discussion of them would of course require much more space.) 
Case 1. Subject B has paid artist A to paint his portrait. At the end of the session the artist hands him her painting $\mathrm{P}$, which consists of an apparently random collection of blobs of paint. Does painting $\mathrm{P}$ externally represent or portray $\mathrm{B}$, and if so, in what sense?

Arguably, this is a case of signification only (no description or picturing) $-\mathrm{P}$ is of $\mathrm{B}$, or about $\mathrm{B}$, only in the sense in which a name is of or about its bearer. Interestingly enough, this would count as a case of signification of B, even if artist A had had no concurrent intentions to portray $\mathrm{B}$ at all while painting the picture, because the social conventions regarding portraiture, as with naming baptisms, are performative in nature: if one performs the requisite actions (painting) in the right social setting of agreedon portraiture, the resultant artifact (the painting P) thereby conventionally counts as signifying the subject. (The internally represented item in such a case would presumably be a pure, nondescriptive pointer to the relevant individual B.)

Case 2. The same initial situation, in which A has been hired to paint B's portrait. This time, A's resultant picture $P$ resembles a slim, short woman - quite unlike the tall, heavy male sitter B. Again, does painting P externally represent or portray $\mathrm{B}$, and if so, in what sense or senses?

As before, $\mathrm{P}$ does signify B for the previous reasons. In addition, some appropriate concept of descriptive representation might now become applicable as well. Intuitively speaking, "slim, short woman" is a possible description-albeit a significant misdescription-of a heavy, tall man, whereas "random blobs of paint" as in case 1, is not a possible misdescription of B.

However, in this case, unlike case 1 , the intentions of painter A are of crucial importance. Unless she intended her picture $\mathrm{P}$ to pictorially represent $\mathrm{B}$, there would be no point in saying that picture $\mathrm{P}$ descriptively represents or misrepresents $\mathrm{B}$; it would not provide any kind of painterly description of B itself-as opposed to some other object, or no object at all-no matter how closely the two descriptively resemble each other. The significant degree of misrepresentation in the present case tends to show that artist A did not have the requisite intention-failing special pleading on her part, such as a claim perhaps that the painting metaphorically depicts the inner feminine side of her thickset subject B.
But then exactly what is descriptive representation? I would claim that (1) no genuine external representation of any kind is involved in such cases, and, hence, that (2) the relevant internally represented object, namely, the slim, short woman in this case, is just an internal representation of $a$ woman, rather than of any particular actual woman or man. Also, the characteristics of the internally represented woman are only descriptively relevant to B at all if picture P's contents include an intention by painter A to depict B.

Thus, presumably, the main utility of a concept of descriptive representation, in cases where depiction has not occurred, would be to duly acknowledge the existence of "near-miss" cases in which both appropriate intentions to depict an object, plus a reasonably good descriptive match, may be inferred or seen to have been achieved. But even so, such cases strictly speaking are not failed depictions of $\mathrm{B}$, since they do not depict (pictorially represent) B in any sense, though they must involve an intention to depict B.

A related case is as follows. In the philosophy of language, "referential" uses of definite descriptions are acknowledged, which achieve reference in spite of incorrect descriptionssuch as someone saying "that man over there is smoking" when the smoker is in fact a woman. $^{18}$

However, there are at least two reasons why there are no analogous referential descriptive misrepresentations among putative pictures. First, there is no close pictorial analogue of the demonstrative linguistic element "that man," supplemented by contextual factors such as a gesture or head turning, which can establish reference independently of the description. And second, descriptive terms in language can function either to identify (as in a definite description) or to predicate a property of a thusidentified item. But in the case of putative pictures, there is not enough structure to distinguish those semantic functions; such a lack would also thwart attempts to establish that there are misrepresenting referential pictures of this specific kind.

The closest quasi-pictorial analogy to referential linguistic misdescriptions would be a distorting mirror, which does establish contextual reference to the objects it shows, and does 
"misdescribe" the characteristics of the relevant objects. However, because of the forward counterfactual dependence of such images on their actual subjects (see Section IV), the relevant objects are not represented at all in such cases; instead, the viewer simply sees the actual objects through the mirror, as distorted by its optical characteristics.

Case 3. A paints B's portrait with the intention of depicting B. But this time, both A and B are happy with the result, in that each can recognize B in the finished portrait. This finally, I would argue, is a genuine case of pictorial or depictive external representation. It would also qualify as a case both of significative and of descriptive representation of B. However, depiction, unlike descriptive representation, is compatible with fairly radical mismatches in descriptive characteristics between picture and subject-that is, with genuinely depictive misrepresentation-as long as recognizability is preserved. ${ }^{19}$

Thus, I claim that a necessary condition of P's externally depicting an actual object $\mathrm{X}$ is that $\mathrm{P}$ be recognizable as $\mathrm{X},{ }^{20}$ with that locution itself being explained in terms of recognizing or seeing the relevant internally represented item $\mathrm{X}^{\prime}$. While at the same time, "near-miss" cases in which recognition is not achieved can be acknowledged to have some representational status - but, nevertheless, be explained away as cases of descriptive, nondepictive representation.

However, recognition by itself does not provide a sufficient condition of external depiction, because "false positives" are possible_-pictures that would be generally recognized as $\mathrm{X}$, but that were not intended to externally depict $X$. Thus, both recognition and intention to depict are required to achieve a sufficient condition of external depiction.

Now recognition can be achieved simply from perception of a picture itself. But can knowledge of the relevant intention to depict be acquired in the same intrinsic manner, or are external or contextual information also required?

To be sure, contextual information is often available in the forms of titles of paintings, catalog descriptions, and so on, rendering the issue moot in those cases. But in the absence of such aids, here is a brief suggestion as to how knowledge of relevant intrinsic artist intentions might be achieved in a central class of cases.
There are stereotypical characteristics associated with well-known people, such as Lincoln's tall, gaunt, and bearded profile. Anyone making publicly available a picture having such characteristics is prima facie implying that the intention was to depict Lincoln, in the absence of any contextual evidence to the contrary. Thus in such cases, the same factors that enable one to recognize that Lincoln is internally represented by the picture also establish artistic intentions to depict Lincoln, which factors taken together are a sufficient condition of the picture's externally depicting Lincoln.

In the next section, I shall use this analysis of pictorial representation in the presentation of the previously sketched (in Section III) epistemic argument for the referential status of the concept of internal representation.

\section{INTERNAL REPRESENTATION}

My strategy with regard to defining and defending internal representation will be threefold: (1) to accept my initial, tentative definition of the concept as a working model, in spite of its apparent difficulties; (2) to use the veridicality of seeing and recognition to justify its referential logic; and (3) to use the briefly sketched epistemic approach to it to justify its conceptual indispensability.

To begin, my initial attempt at a characterization of internal representation was this: internal or inner representation is about whether there is an object $\mathrm{X}^{\prime}$, that is internal to the object $\mathrm{P}$ and that is represented by $\mathrm{P}$. For example, picture $\mathrm{P}$ internally represents a man, just in case there is a man, who is internal to $\mathrm{P}$ and who is represented by $P$.

As announced, I shall accept this characterization and justify it as follows. First, if a person with normal perceptual abilities, ${ }^{21}$ under normal lighting conditions, sees a picture of a man, he will be able to see a man when he looks at it, or equivalently, he will be able to recognize what he sees as a man-assuming the picture is successful in representing a man, that is, that similar normal people under normal conditions can see or recognize a man when they look at it. $^{22}$

Thus, one's primary evidence as to whether a picture A is successful in representing a man 
(whether or not it externally represents a particular man) is derived from evidence regarding the general abilities of people to see or recognize a man when perceiving that picture A. For whatever the intentions of the person making the representation, she will only have succeeded in representing $\mathrm{X}$ if those general recognitional conditions are satisfied.

However, the concepts of seeing and recognition are veridical concepts, such that a claim to see or recognize $\mathrm{X}$ is true only if there is an $\mathrm{X}$ that one sees or recognizes. Thus, if it is true that one sees a man $\mathrm{X}$ when perceiving picture $\mathrm{A}$, then there must be a man $\mathrm{X}$ whom one sees-or one did not, after all, see or recognize such a man $\mathrm{X}$ when perceiving the picture.

Hence, short of a massive "error theory" of ordinary reports of seeing or recognizing pictures, which would deny that we ever really do see or recognize items when seeing pictures, our ordinary epistemic claims to see or recognize $\mathrm{X}$ when perceiving A should be respected, as requiring us to accept that there is an internal $\mathrm{X}$ that is thereby seen or recognized, and, hence, to accept the current referential characterization of internal representation being argued for.

Now, it might be thought that this conclusion is premature, on the ground that seeing or recognizing $\mathrm{X}$ when perceiving a picture might be a case of external rather than internal representation. However, it has already been established in Section IV that strictly speaking one cannot see the actual object $\mathrm{X}$, in seeing a picture of $\mathrm{X}$ that externally represents $X$. Hence, all one can do instead is to see or recognize the internal object $\mathrm{X}^{\prime}$ - a case of internal representation.

Now, as already pointed out, the ability to see a man while looking at a picture, or the recognition of what one sees as a man, is a skill independent of whether or not the picture also externally represents some particular actual man. Nevertheless, there is an important connection of such "internal" abilities with external representation as well, in that, I shall briefly argue, it is in virtue of seeing what a picture $\mathrm{P}$ internally represents (its object $\mathrm{X}^{\prime}$ ) that one can justify a claim that $\mathrm{P}$ externally represents object $\mathrm{X}^{23}$ - given the failure of justifications in terms of "seeing-through" approaches.

The basic reason why external representation claims are epistemically dependent on internal representation claims is because of the conjunc- tion of the following three points that have already been presented separately; namely, (1) claims of successful representation require perceptual or recognitional evidence, since mere evidence of artistic intentions to represent $\mathrm{X}$ does not demonstrate success in doing so; (2) the only perceptual or recognitional evidence available is of internal representational kinds, since strictly speaking one cannot see or recognize a picture as externally representing $\mathrm{X}$; and (3) as claimed in the previous section, recognition of an internally represented object is a necessary condition of external representation of its actual counterpart, and it becomes a sufficient condition when reinforced by intent to externally represent $\mathrm{X}$, which normally follows as a matter of course via the prima facie intentions of those making their pictures publicly available.

To be sure, one might believe that one sees that a picture externally represents Napoleon, but one cannot actually see it thus even if the picture is an external representation of Napoleon, for the reasons already given (because of "no seeing through" plus the veridicality of the concept of seeing). Hence, such claims of perception or recognition of external representation need to be reworked as objective, perceptionindependent claims about what a picture itself externally represents - but the only perceptual or evidential support available for such objective claims is from internal representational sources.

Now, a full justification of a claim that picture $\mathrm{P}$ externally represents an actual man $\mathrm{X}$ would presumably require much more recognitional evidence than merely that one can internally see picture $\mathrm{P}$ as $a$ man, or see a man when one looks at it - presumably, one also must be able to see it as a man of a certain sort, or as a man having further, sufficient identifying characteristics. But the ability to internally see a man when one looks at the picture remains as a primary, evidentially necessary condition for external representation of the actual man X.

I take these points as showing that the epistemic foundations of internal representation are at least as secure as those of external representation, so that any potential attacks on my account of internal representation as somehow being "unfounded" or "subjectivist" have already been defused to a significant extent. 
Next, I claim that the overt or intuitively natural logical form of statements of internal representation - that there is an object $\mathrm{X}^{\prime}$, that is internal to the object $\mathrm{P}$, and that is represented by $\mathrm{P}$ - can itself be given an epistemic defense, in that the evidential chain justifying claims of external representation itself requires that the internal epistemic evidence have such a logical form, that is, a logical form in which a particular "internal" entity is referred to and reidentified as being represented by $P$.

To begin with, it has already been established that a claim to see a man when looking at picture $\mathrm{P}$ is, on the face of it, unavoidably referential-that is, implying a claim that there is a man whom one sees. An additional reason for accepting that point is that statements reidentifying that same man play an essential role in the epistemic justification of claims of external representation by a picture.

This is so, because justification has a social dimension: in order to justify a claim that picture $\mathrm{P}$ externally represents an actual man X, there must be intersubjective agreement on the evidence for that claim. This requires that different persons must each be able to see picture $\mathrm{P}$ as internally representing the same man $\mathrm{X}^{\prime}$, since otherwise the evidentiary basis for the external representation claim - the fact that a man $\mathrm{X}^{\prime}$, that is, the same man $\mathrm{X}^{\prime}$ in each case, can be seen by qualified observers when looking at picture $\mathrm{P}$-will fail to be established.

For example, suppose that two people, A and $\mathrm{B}$, look at the same picture $\mathrm{P}$, and that each claims, on the basis of what he sees, that the picture externally represents Napoleon. If asked for the evidentiary basis of his claim, A replies that he can see, recognize, or identify the man in the picture as Napoleon-that is, that the man internally represented by the picture is recognized by him as being Napoleon. And suppose that person $B$ gives the same reply to the question.

Now, my claim is that for B to be corroborating A's claim, it must be assumed or presupposed that each is talking about the same man in the picture. For if A were to recognize one man $\mathrm{X}$ in a picture, and $\mathrm{B}$ were to recognize another man $\mathrm{Y}$ in the same picture, then there would be no single man $\mathrm{Z}$ such that both $\mathrm{A}$ and $\mathrm{B}$ recognize him as being Napoleon, and, hence, no secure ground for social agreement that the picture therefore externally represents Napoleon.

Indeed, so basic is this point that one can hardly even make sense of the claim that $\mathrm{A}$ and $\mathrm{B}$ might be recognizing different men in the picture-other than in the everyday sense that the picture might represent two distinct men, so that $\mathrm{A}$ and $\mathrm{B}$ might be talking at cross-purposes about those different men, which are visible in different areas of the picture.

To be sure, nonreferential analyses of what I am calling "internal representation" might attempt to deny all of this; but my point is that the possibility of reidentification of the same internal object of reference is a cornerstone of an epistemically defensible account of representation.

Hence, I would claim, the overt or intuitive logical form of statements of internal representation cannot be overturned without at the same time overturning our whole present scheme of justification of claims that some pictures do indeed externally represent certain actual things (again, given the inadequacy of "seeing-through" views for this task). Thus, the referential logical form of statements of internal representation is arguably at least as secure as is the referential logical form of statements of external representation, under our present scheme of justification.

\section{ACTUAL VERSUS REPRESENTATIONAL TRUTH}

On the present view, statement-forms such as "picture P represents object X" are ambiguous between internally versus externally represented objects. But this also means that descriptions of the relevant objects are similarly ambiguous. Thus, we need to distinguish actual truths about externally represented objects, from internally represented or representational truths, which are specifically about internal objects as such.

Thus, for instance, a picture of Napoleon is such that it is true of the person as internally represented in the picture that he is Napoleon, since he can be seen to be Napoleon by any culturally competent person looking at the picture, so that "he is Napoleon" is a representational truth about the person thus seen. But this representational truth about the object that can be seen in the picture should not be confused with an actual truth about the real person Napoleon 
himself-for, as argued in Section IV, the person thus seen in the picture could not be identical with the actual person Napoleon.

Nevertheless, there can be actual truths about internally represented objects, of a broadly extrinsic kind concerning the relations of internally represented objects to the real world. For example, it is actually true of the object seen in the picture as Napoleon that it is represented by the picture as being Napoleon, and that it is not identical with the real person Napoleon.

The distinction between representational versus actual truths is in part already a familiar one, for there is an important proper subset of representational truths, namely, fictional truths, that have been widely discussed in the literature. ${ }^{24}$ For, although the category of representational truths in general applies to any kind of internally represented object, whether or not there are any corresponding externally represented entities, the subcategory of fictional truths applies only to internal objects that have no corresponding actual object that is externally represented.

I shall discuss the status of such "fictional objects" and fictional truths about them in the following two sections.

\section{THE LOGICAL STATUS OF FICTIONAL ENTITIES}

I shall now show how the current view enables a fresh, and arguably improved, account to be given of the logical status of discourse involving talk about fictional entities. The basic idea is this. First, there are, of course, no such actual entities, so that their ontological status, as things that do not exist, is already established. ${ }^{25}$

Second, since none of these entities actually exist, there are no legitimate cases of external representation of them. Third, consequently, any apparent references to such entities should be construed as being cases of internal representations of such entities-whether of linguistic, pictorial, or other representational kinds-in which some representing object internally represents, thus refers to, an internal object. ${ }^{26}$ And fourth, an account of fictional truth-as opposed to actual truth-for such internal fictional entities is then potentially available, along the lines sketched in the previous section for the broader concept of representational truth.
This treatment has several related advantages over more conventional accounts. First, in support of its account of fictional truth, a related distinction between "internal" versus "external" statements-and between differing kinds of truth-conditions for each-is often made in discussions of fictional characters. For example, an internal statement such as "Hamlet is the prince of Denmark" is fictionally true, while an external statement such as "Hamlet is one of Shakespeare's most complex characters" is externally or actually true. ${ }^{27}$ But, on my account, it is possible to construe both kinds of statement as being about the same fictional character: internal statements describe its intrinsic characteristics, whereas external statements describe its extrinsic characteristics that link it to the actual world. Also, this account is able to preserve the referential form of such fictional discourse, since, as argued previously, internal representation is and must be logically referential.

In addition, the possibility of genuine reference to specifically fictional entities is guaranteed by the necessity of our being able to genuinely refer to (internal versions of) any kinds of entities whatsoever. Thus, no "special pleading" is required to legitimate cases of fictional reference, which, as referents of the ontologically neutral kind of reference involved in internal representation, are in no way anomalous, or in need of special explanation.

A related point is that what characterizes fictional entities as specifically or essentially fictional is something about their external representational status, namely, that there are no external representations of them. But their internal representational status, as just noted, is one they share with every other kind of entity that is internally representable.

\section{MORE ON THE STATUS OF FICTIONAL ENTITIES}

As noted in the previous section, it is generally agreed that fictional entities do not exist. But this basic fact is often held to be fatal, or at least theoretically intractable, for a broadly referential account of fictional entities such as mine. For on a conventional theory of representation, according to which all representation is external representation, there are only two possibilities if there are no objects to externally represent: 
either one must give a nonreferential account of the representation of such objects-which would be fatal to my theory-or one must appeal to a special class of "fictional objects" that would serve as the referents of external representations of them, in spite of the fact that such objects are agreed not to exist.

Such theories could be described as broadly Meinongian, ${ }^{28}$ in that they hold that some objects, in spite of not existing, can nevertheless "subsist," or have "being," and so on. But, although other such theories have been constructed, ${ }^{29}$ it is unclear to me at least that the theoretical complexities involved in such theories have any decisive payoff in terms of increased theoretical understanding, or explanation, of the nature of fictional entities-hence, my comment that this kind of approach is theoretically intractable or unrewarding.

Now I shall introduce another basic feature of the distinction between external and internal representation. In the external case, the object represented is of course both logically and ontologically independent of the object that is externally representing it. It is this fact that, I would argue, is the basic reason why Meinongian theories are so theoretically elusive or unrewarding, because such entities are freestanding, independent entities whose status as objects of reference, or as objects having an ontology of a certain kind, has no obvious support of any kind beyond the need to postulate such entities, if this approach is to be adopted.

On the other hand, in the case of internal representation, a case could be made that the relevant objects of reference are in some appropriate sense referentially dependent on the actual objects that internally represent them, in that the actual existence of those representing objects in some way underwrites or guarantees the availability as objects of reference of appropriate internally represented objects.

As evidence for this claim, it is perhaps obvious that one cannot see a man, as internally represented by a picture $\mathrm{P}$, without directing one's gaze upon that same physical picture $\mathrm{P}$, so that one's epistemic access to an object that $\mathrm{P}$ internally represents is epistemically dependent on one's having access to $P$ itself ${ }^{30}$ — from which epistemic dependence one may make appropriate inferences to a corresponding kind of internal referential dependence. Or, as a related point, one may appeal to the representational powers of a given physical object, as provided by its physical design or configuration, as an explanation of how it is possible for it to internally represent some appropriate object of reference.

This approach may also be used to explain apparent cases of artistic creation of fictional characters and events in fictional works. First, it would seem to be true in some sense that Shakespeare "created" the character Desdemona in his play "Othello." But, if Desdemona was created, then how do we avoid the conclusion that therefore Desdemona exists —or at least has some kind of Meinongian "being"?

On the current approach, we can instead say that what Shakespeare actually created, and what does indeed exist, is a textual representation of Desdemona-as part of his original manuscript of his play "Othello"-rather than the character herself. But that representation nevertheless made Desdemona available as an object of internal reference of that created representation.

This account is not yet complete, for the possibility of there being many distinct physical representations of the play, each being able to make reference to the same internal character Desdemona, still needs to be explained. In this connection, I have elsewhere invoked the concept of an originative representation, ${ }^{31}$ which is one that is intended by its author both to be a definitive representation of the play and its characters and to be usable by him or others to make authorized copies of that representation, which are, in turn, intended to represent the same characters.

Thus, on this account, there is an irreducibly intentional element involved in any reidentification of the same character, as internally represented by distinct representations of her-and this is a necessary feature of a satisfactory account, for it is generally acknowledged that mere qualitative identity of representing objects, as in cases of two texts being word for word identical, is not sufficient for the identity of any associated characters or artworks. ${ }^{32}$

At the same time, this possibility of reidentification of an internal object across different representing objects is arguably itself a necessary feature of any genuinely referential account of fictional or other objects-since without that 
kind of objective, or at least intersubjective, status of internal objects made possible by this account, talk of "reference" to, or "reidentification" of, such entities by various people in different situations would be a mere sham. ${ }^{33}$

There are at least two other ways of arguing that reference to fictional characters is possible. An "ordinary language" approach would argue that, since references to, and reidentifications of, fictional characters are common in everyday linguistic practices, such uses need no additional justification beyond their bedrock linguistic status.

A related but more sophisticated approach would distinguish a "surface" level or theory of fictional reference from possible deeper theories, which might or might not maintain genuine reference to fictional entities. (I argued for such a "surface" approach as one form of legitimate theorizing about reference to fictional entities in a previous paper. ${ }^{34}$ )

Intuitively, the idea is that such a surface theory could be genuinely true, and explanatory, as applied to surface phenomena, such as everyday linguistic references to fictional characters, whether or not a deeper or more reductive theory might explain—or explain away—such apparent references in other terms. On such a surface view one can both acknowledge what is valid in "ordinary language" approaches, yet also allow the possibility of more fundamental levels of theorizing.

But now that the current account of reference to fictional entities in terms of internal representation is available, I would claim that it provides the only necessary deep theory of fictional entities - to complement, underlie, and explain the just-discussed surface theory. Thus, on my account, fictional reference is genuine in both surface and more fundamental theoretical ways.

\section{CONCLUSION}

To conclude, here is a brief summary of the argument of the paper. In the introduction the apparent ambiguity of statements such as "picture P represents object X" was introduced, along with a preliminary definition of internal representation as " $\mathrm{P}$ internally represents object $X^{\prime}$." Section I allayed concerns about reference to an internal object, in that such references are not existence-entailing, while Section II pointed out the prima facie epistemic unavoidability of two distinct concepts of representation, in cases where a perceiver is ignorant of the external representational status of a picture.

Section III sketched another epistemic argument-spelled out in Section VI-according to which, even in a case where a picture $\mathrm{P}$ does externally represent an object $\mathrm{X}$, the concept of internal representation still has an important epistemic role to play in establishing that fact. Section III also introduced two possible objections to my account: first, a "seeing-through" objection that would replace apparent cases of internal representation with perception of actual externally represented objects, which account I refuted in Section IV. And second, an alternative nonreferential account of apparent internal representation cases was sketched, which I later indirectly rebutted in Section VI via arguments there that imply that it could not provide a complete account of all representational cases.

Section IV argued for the impossibility of "seeing through" a representation to the object it externally represents, for example, because genuine representations, unlike "visual prostheses," are not forward counterfactually dependent on externally represented objects. Section V maintained the internal versus external ambiguity of representation in a broader context of conventional and intentional factors, distinguishing genuine representation from mere name-like signification and a supposed "descriptive representation," while also claiming the necessity and joint sufficiency, for external representation, of recognition of an internally represented object plus intention to externally represent.

Section VI drew on previous results, plus the veridicality of the concepts of seeing and recognition, to argue both that recognition is of an internally represented object $\mathrm{X}^{\prime}$, and that it is in virtue of seeing such an object $X^{\prime}$ that one can justify a claim that $\mathrm{P}$ externally represents the corresponding actual object $\mathrm{X}$, so that the epistemic and logical status of internal representation is at least as secure as that of external representation.

Section VII distinguished actual from representational truths, while Section VIII described the advantages of a view of fictional objects as internally represented objects. And finally, 
Section IX argued for the referential and epistemic dependence of such objects-which helps to distinguish them from theoretically suspect Meinongian objects-while also arguing that the current "internal representation" view provides a deeper theoretical justification for previous views of fictional reference. ${ }^{35}$

\section{JOHN DILWORTH}

Department of Philosophy

Western Michigan University

Kalamazoo, Michigan 49008

\section{INTERNET: Dilworth@wmich.edu}

1. Richard Wollheim, Painting as an Art (Princeton University Press, 1987), pp. 67-71.

2. Kendall L. Walton, Mimesis as Make-Believe: On the Foundations of the Representational Arts (Harvard University Press, 1990), chap. 3.

3. Nelson Goodman, Languages of Art: An Approach to a Theory of Symbols (Indianapolis: Bobbs-Merrill, 1968), chap 1.

4. Although there may be special cases of an object externally representing itself, or parts of itself, that straddle the distinction being made here, I shall ignore such cases in what follows.

5. Thus, I shall not consider more generic kinds of representation in which, for instance, a picture of a man in an encyclopedia might be considered as making plural reference to men, or to any actual man, rather than to a particular actual man.

6. I distinguish my account from a Meinongian account of reference to nonexistent objects in Section IX.

7. Thus, my account has some affinities with Brentano's concept of the "intentional inexistence" of intentional objects, though such connections will have to be explored elsewhere.

8. Goodman, Languages of Art: An Approach to a Theory of Symbols, pp. 21-26.

9. Interestingly enough, Goodman himself can be construed as arguing that "picture of a man" is ambiguous between a relational versus a nonrelational, sortal ("manpicture") interpretation. But his view still supports a unitary view of representation, according to which only external representation is genuinely relational.

10. However, arguably, the standard view of representation, based as it is on external representation, is itself ad hoc in an inverse way, in that it cannot be generalized to cover cases when there is no externally represented object.

11. This is not to attack the concept of representational content itself, but only an appeal to it as supposedly preempting the postulation of such an object $\mathrm{X}^{\prime}$.

12. And in general, a picture of an $\mathrm{X}$ is not itself an $\mathrm{X}$ representations are not instances of the things they represent.

13. Kendall Walton holds such a view for photographs in "Transparent Pictures: On the Nature of Photographic Realism," Critical Inquiry 11 (1984): 246-277, while Dominic Lopes extends it to pictures generally in his book Under- standing Pictures (Oxford University Press, 1996), chap 9. For a critique of such views independent of mine, see Nigel Warburton, "Seeing through 'Seeing through Photographs,", Ratio 1 (1988): 64-74.

14. Or, more precisely, under these conditions it is not functioning as a representation of $\mathrm{X}$ : there might, for instance, be cleverly constructed binoculars that both externally represent $\mathrm{X}$ when one looks at rather than through them, but that nevertheless enable one to see $\mathrm{X}$ itself when one does look through them.

15. Walton, "Transparent Pictures: On the Nature of Photographic Realism," and Lopes, Understanding Pictures.

16. A thesis that all aspects of content or meaning may be explained in terms of internal representation will not be defended here, though, on my view, it is defensible.

17. My thanks to the editor, Susan Feagin, for suggesting the relevance of such cases, and of analogous cases in the philosophy of language such as the one discussed below.

18. See, for example, Keith Donnellan, "Reference and Definite Descriptions," Philosophical Review 75 (1966): 281-304.

19. Antonia Phillips provides a convincing account of the centrality of recognition in portraiture in her paper "The Limits of Portrayal," in Philosophy and the Visual Arts, ed. A. Harrison (Dordrecht, The Netherlands: Reidel, 1987), pp. 317-341.

20. Arguments for this view are given in my paper "Representation and Resemblance," The Philosophical Forum 12 (1980): 139-158, while Lopes, Understanding Pictures, and Phillips, "The Limits of Portrayal," provide other arguments for recognitional views of representation. The following section also provides relevant arguments.

21. By "normal" here I mean only the basic perceptual competencies possessed by almost everyone, independent of more uncommon additional abilities to make sophisticated artistic perceptual discriminations.

22. Lopes, Understanding Pictures, gives a useful account of some relations between recognition and representation, though he assumes a unitary concept of representation.

23. Lopes, Understanding Pictures, provides a survey of various factors possibly relevant to justification.

24. See, for example, Walton, "Transparent Pictures: On the Nature of Photographic Realism," and the references therein.

25. However, an account is still possible of the sense in which it is true that Hamlet exists in the fictional world of the play "Hamlet." See my paper "The Fictionality of Plays," The Journal of Aesthetics and Art Criticism 60 (2002): 263-273. Also see my "Theater, Representation, Types and Interpretation," American Philosophical Quarterly 39 (2002): 197-209.

26. See my "The Fictionality of Plays."

27. See, for example, my "The Fictionality of Plays," and the included references.

28. Alexius Meinong, "On the Theory of Objects," in Realism and the Background of Phenomenology, ed. Roderick Chisholm (Glencoe, IL: Free Press, 1960), pp. 76-117.

29. For example, Terence Parsons, Nonexistent Objects (Yale University Press, 1980).

30. In my "The Fictionality of Plays" I provide ancillary discussions of the epistemic authority of representations in 
helping to determine the internal truth-conditions for fictional statements.

31. In my "A Representational Theory of Artefacts and Artworks," The British Journal of Aesthetics 41 (2001): 353-370, and "The Fictionality of Plays."

32. As Borges showed, on one interpretation of his story, with his well-known example of a fictitious work by one "Pierre Menard," the text of which was word for word identical with the text of a section of Cervantes's Don Quixote, but whose aesthetic qualities were quite different, hence, ensuring its identity as a literary artwork distinct from the relevant part of Don Quixote itself. Borges, "Pierre Menard, Author of the Quixote" in Labyrinths, (Harmondsworth, Middlesex: Penguin, 1985).

33. See also Section VI on this point.

34. "The Fictionality of Plays."

35. My thanks to the editor, Susan Feagin, and to an anonymous referee of The Journal of Aesthetics and Art Criticism for very helpful comments. 